УДК 004.9

10.17213/2075-2067-2021-4-188-194

\title{
ВЛИЯНИЕ ЦИФРОВОЙ ТРАНСФОРМАЦИИ НА ИННОВАЦИОННОЕ РАЗВИТИЕ ПРОМЫШЛЕННЫХ ПРЕДПРИЯТИЙ
}

\author{
() 2021 г. Д. Ю. Фраймович, К. А. Власенко, А. И. Усова \\ Владимирский государственный университет \\ имени Александра Григорьевича и Николая Григорьевича Столетовьх, \\ 2. Владимир, Россия
}

Цель исследования. В статье приводится обоснование значения циифровой трансформации для современной рыночной экономики на примере промышленных предприятий, выляляются причины, методы, сложности реализации циирровой трансформации в авиационной отрасли, а также раскрывается необходимость мониторинга социально-экономических последствий высокотехнологичных изменений.

Методы исследования базируются на данных о реализации иүифровой трансформации промышленности и авиационной отрасли на основе сведений федеральных законов РФ, постановлений Правительства РФ, наџиональной программы «Цифровая экономика РФ», официальных статистических данных.

Результаты исследования. На примере деятельности авиационной компании S7 Airlines, a также ряда промышленных предприятий доказано, что благодаря ичифровой трансформации инновационные проекты обеспечивают максимально эффективное развитие промышленности РФ. Однако возникает необходимость мониторинга сочиильно-экономических последствий данного процесса в связи с широким спектром последствий изифровизачии экономики и общественной жизни РФ и недостаточностью методологического обоснования влияния циифровизации на развитие промышленных предприятий.

Перспективы исследования. Определение индикаторов ичировой трансформации соииально-экономических систем позволит идентифицировать факторы, играющие ключевую роль в народнохозяйственных и инновачионных процессах, а также оптимизировать инструменты стратегического управления в региональном и национальном маситабах.

Ключевые слова: ичирровая трансформация; промышленные предприятия; инновационное развитие; мониторинг сочиально-экономических последствий.

\section{THE IMPACT OF DIGITAL TRANSFORMATION ON THE INNOVATIVE DEVELOPMENT OF INDUSTRIAL ENTERPRISES}

\section{(C) 2021 D. Yu. Fraimovich, K. A. Vlasenko, A. I. Usova}

\section{Vladimir State University named after Alexander and Nikolai Stoletovs, Vladimir, Russia}

The purpose of the study. The article substantiates the significance of digital transformation for the modern market economy on the example of industrial enterprises, identifies the reasons, methods, and difficulties of implementing digital transformation in the aviation industry, and also reveals the need to monitor the socio-economic consequences of high-tech changes. 
The research methods are based on data on the implementation of the digital transformation of industry and the aviation industry on the basis of information from federal laws of the Russian Federation, Government resolutions of the Russian Federation, the national program «Digital Economy of the Russian Federation", and official statistics.

The results of the study. Using the example of the activities of the S7 Airlines aviation company, as well as a number of industrial enterprises, it is proved that thanks to digital transformation, innovative projects ensure the most effective development of the Russian industry. However, there is a need to monitor the socio-economic consequences of this process due to the wide range of consequences of digitalization of the economy and public life of the Russian Federation and the lack of methodological justification of the impact of digitalization on the development of industrial enterprises.

Research prospects. The identification of indicators of digital transformation of socioeconomic systems will allow identifying factors that play a key role in national economic and innovation processes, as well as optimizing strategic management tools at the regional and national scales.

Key words: digital transformation; industrial enterprises; innovative development; monitoring of socio-economic consequences.

Введение. Высокотехнологичные изменения прошлых лет, затронувшие практически все народнохозяйственные сферы, заставляют общество, бизнес и государство кардинальным образом перестраивать механизмы взаимодействия, постоянно апробировать и внедрять нестандартные решения, ориентированные на укоренение достижения результатов. В целях выгодного взаимодействия государства и бизнеса крупными компаниями-лидерами создана организация «Цифровая экономика». Ее развитие осуществляется при поддержке Администрации Президента РФ и Правительства РФ. Благодаря данной программе реализуются научные и прикладные исследования в сфере цифрового развития, что позволяет предприятиям практически применять цифровые технологии, успешно осуществляя цифровую трансформацию, тем самым повышая уровень конкурентоспособности, и эффективно развиваться, выходя на международную арену [5].

Цифровая трансформация осуществляется посредством применения «сквозных» технологий. Каждое предприятие имеет свою специфику инновационно-технологического развития и соответственно уровень подготовки к реализации цифровой трансформации, поэтому наблюдается неравномерность в осуществлении данного процесса.
Цифровая трансформация имеет серьезные отличия по сравнению с процессом автоматизации производственного процесса, заключающиеся в эффективном управлении бизнеспроцессами, организационными изменениями, а не только в осуществлении преобразований технического и технологического уровня [2].

На основании проведенного исследования MuleSoft в 2021 году цифровая трансформация на мировом уровне осуществляется с учетом таких тенденций развития, как:

1) готовность к реализации цифровой трансформации - возникает все большая необходимость проводить цифровизацию и глобализацию производства и оказания услуг для того, чтобы обеспечить удовлетворение потребительских запросов;

2) демократизация инноваций - информационным отделам важно поощрять самостоятельную инициативу развития компаний;

3) компонуемость предприятий - усиление гибкости без постоянного создания новых цифровых приложений, а развитие посредством компилирования уже имеющихся разработок с помощью АРI;

4) уровень автоматизации - увеличение операционной активности предприятий и бизнес-процессов с помощью АРI;

5) безопасность API - соблюдение строгих мер для обеспечения безопасности развития инновационного развития; 
6) наличие организационных микросервисов - данные сервисы позволяют осуществлять быстрое и эффективное принятие управленческих решений с целью совершенствования пользовательского опыта;

7) осуществление интеграции данных возникает необходимость быстрых и результативных методов извлечения неважной информации из данных;

8) использование аналитических платформ - имеет значение для совершенствования опыта клиентов, повышая при этом важность аналитических данных [3].

Постановка проблемы. Благодаря реализации цифровой трансформации промышленные предприятия осуществляют переход на новый технологический уровень, что позволяет повысить им конкурентные позиции не только в РФ, но и на международном уровне.

Обрушившаяся на мир пандемия в связи с распространением коронавирусной инфекции выступила мощнейшим двигателем развития экономики цифрового типа. Предприятия и организации были вынуждены организовать работу в удаленном режиме.

Однако стоит отметить, что в РФ для некоторых отраслей путь к цифровой трансформации имеет ряд сложностей. Многие заводы нашей страны осуществляют свою производственную деятельность на старом, зачастую устаревшем, оборудовании. Перенести данные такого оборудования в цифровую среду невозможно, а значит, и создание их цифровых двойников невыполнимо. Для того чтобы обновить производственные мощности, предприятиям не хватает имеющихся инвестиций. Таким образом, действительность российской промышленности такова, что многие предприятия продлевают сроки эксплуатации оборудования, а полный переход к цифровым технологиям для них остается закрытым вопросом.

На рисунке 1 графически представлена динамика доли инновационных продуктов в обрабатывающей промышленности [2].

Динамика, изображенная на рисунке 1, является нестабильной. Наибольший процент инновационных продуктов наблюдался в 2013 году, после чего произошло снижение данного показателя. За 9 анализируемых лет рост составил всего $1 \%$.

В настоящее время количество инновационных промышленных предприятий в России составляет около $11 \%$, а число занятых в высокотехнологичных/наукоемких отраслях в России - $4 \%$ [9].

Для того чтобы конкурировать на рынке, предприятиям необходимо производить высокотехнологичные изделия, потребительские свойства которых будут качественно сравнимы с изделиями конкурентов. Реализовать это, существенно не повысив цену, возможно только за счет цифровой трансформации.

Примерами предприятий, выбравших данный путь развития, можно назвать ПАО «КАМАЗ», концерн «Калашников», «РусАл», «Петрозаводскмаш», «Вертолеты России»,

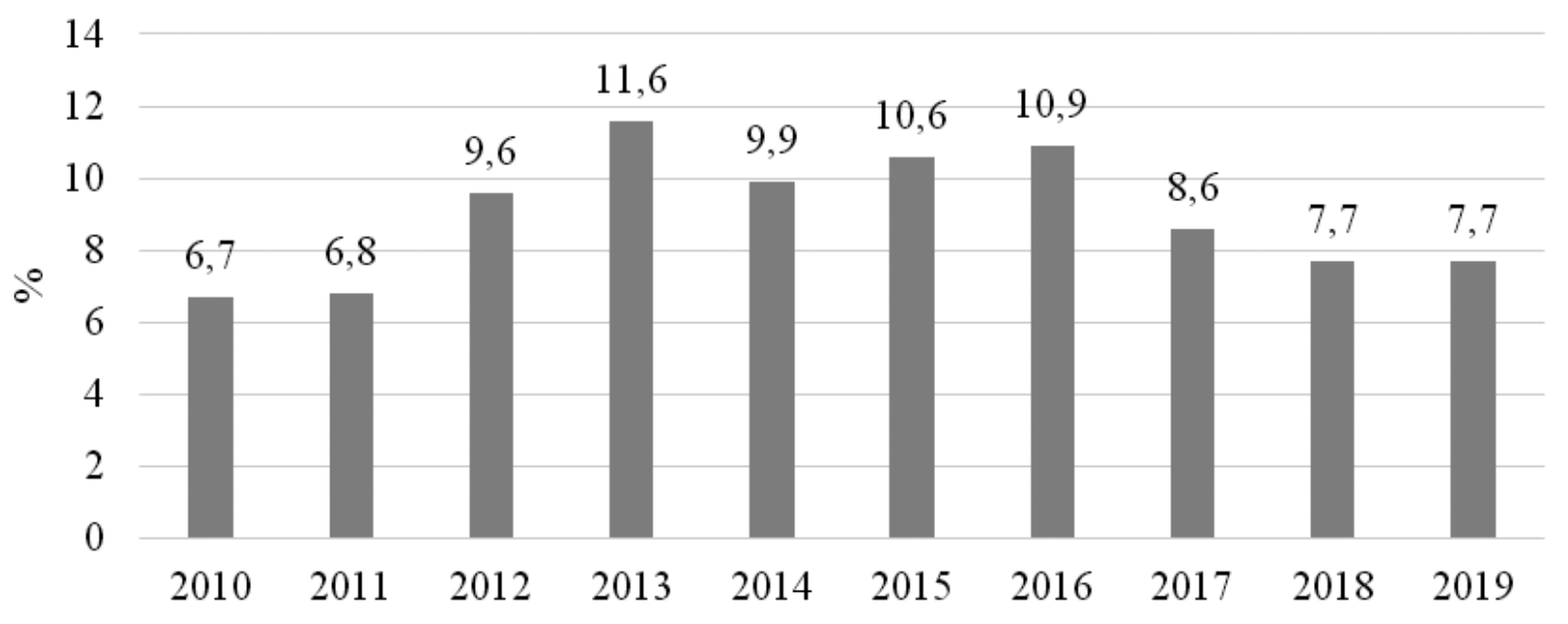

Рис. 1. Удельный вес инновационных товаров, работ, услуг в общем объеме отгруженных товаров в обрабатывающей промышленности 
«ОАК». Благодаря передовым технологиям компании модифицируют свое производство и оптимизируют бизнес-модели.

Специальный «Центр цифровой трансформации» создан на базе ПАО «КАМАЗ», при помощи которого общество успешно реализовывает различные проекты: благодаря цифровой трансформации ПАО «КАМАЗ» за 1 год повысил уровень продаж на 21 \% [7].

Успешно осуществляется цифровая трансформация в отраслях авиационной промышленности. В данном случае активно используется создание цифровых близнецов воздушных суден и их составных частей. При помощи цифровой копии в авиапромышленности возможно моделирование процессов функционирования реального объекта и отдельных систем. Данная модель позволит определить возможные ошибки, отработать сценарии чрезвычайных ситуаций, сократить время на тестовые испытания. Несмотря на то, что в данной промышленности цифровая трансформация реализуется, изменения проходят поэтапно и параллельно с проверенными годами технологиями.

S7 Airlines - российская авиационная компания, входящая в десятку самых популярных авиакомпаний европейского уровня. В данной компании реализация цифровой трансформации началась с 2016 года. Причиной этого выступило желание компании уменьшить производственные издержки, максимизировать прибыль.

Предприятие применяет в своей работе машинное обучение и Big Data в области технического обслуживания самолетов [6]. Компания успешно осуществила формирование собственной системы управления контентом - CMS Cabin.

В 2020 году произошла полная переработка функционального блока по поиску авиационных билетов и определение с направлениями перелета посредством автоматического индивидуальных предложений для клиентов.

Компания заключила цифровой смартконтракт в системеAFS с поставщиком топлива с целью удобства при определении со стоимостью топлива и его объемом. В 2019 году сотрудничество компании с Cisco позволило повысить эффективность осуществляемой деятельности посредством переезда в новый офис и закупки новейшего оборудования и одновременно с этим экстренного монтажа большого числа оборудования, не теряя при этом часть серверов.

В период распространения коронавирусной инфекции была реализована программа S7 Care, предполагающая осуществление защиты пассажиров во время перелетов посредством поэтапной посадки на борт, проведения санитарной уборки и дезинфекции самолетов, предоставление индивидуальных средств защиты пассажирам.

Компания реализовала проект по созданию пользовательских онлайн-путеводителей на территории РФ, созданных на основе фото и рекомендаций в Instagram-ленте.

Нельзя сказать, что переход к цифровой трансформации осуществлялся быстро и беспроблемно. Компания столкнулась с такими сложностями, как качество и доступность данных. Поначалу было трудно внедрить разработки в бизнес-процессы предприятия. Необходимость внесения изменений в управленческие решения также вызывала проблемы, так как наблюдалось сопротивление изменениям. Внедрение инноваций в деятельность компании вызывало также недоверие со стороны заказчиков, поскольку они доверяют только конкретному практическому результату.

Но, несмотря на все возникающие противоречия и проблемы, компания смогла успешно реализовать цифровую трансформацию и достичь положительных результатов: повысить уровень выручки и уменьшить расходы на операционный тип деятельности. Соответственно, процесс цифровой трансформации положительно повлиял на доходность предприятия, продажу билетов на самолеты и процессы управления. Благодаря оптимизации промывок двигателей самолетов компания смогла уменьшить расход топлива на $0,5 \%$.

Говоря о позитивных и негативных аспектах воздействия цифровой трансформации на процесс становления и развития авиационной промышленности, необходимо также отметить, что нельзя сразу учесть возможные последствия и перспективы. Однако в современных реалиях все большую актуальность приобретает стратегическое планирование, позволяющее формировать наиболее благоприятные параметры развития экономики 
посредством мониторинга социально-экономических последствий цифровой трансформации как экономики страны в целом, так и конкретно промышленности.

Система стратегического управления и мониторинга социально-экономических последствий разрабатывается на основании нормативно-правовых актов законодательства РФ для обеспечения национальной безопасности страны, находится лишь на стадии становления и не имеет широкого практического применения в РФ. Распространение коронавирусной инфекции во время пандемии COVID-19 ускорило процесс обновления национальной экономики РФ в условиях цифровой трансформации, а также необходимость проведения данного мониторинга [4].

При проведении мониторинга социально-экономических последствий цифровой трансформации в экономике РФ необходимо обладать информацией, связанной с уровнем доступности получения цифровых услуг населением, состоянием качества оказываемых цифровых услуг, уровнем доверия потребителей полученными цифровыми услугами, а также предъявляемыми к ним требованиями [3].

Мониторинг основывается на формировании базы данных для оценки внесенного вклада экономики страны в ВВП. В то же время возникают проблемы, связанные с отсутствием конкретных рамок в цифровой экономике, нехваткой методик исследования для проведения макроэкономического анализа.

Заключение. Многие компании показали на своем примере, что реализуемые в рамках цифровой трансформации инновационные проекты весьма эффективны и позволили им в короткие сроки выйти на высокий уровень развития, занять конкурентоспособную позицию в мировом масштабе.

Таким образом, цифровая трансформация даст возможность предприятиям осуществлять производственную деятельность максимально эффективно. Это длительный поэтапный путь внедрения инновационных технологий с параллельным ведением традиционных процессов к полному переходу в цифровую среду, который не может осуществляться без осуществления мониторинга социально-экономических последствий цифровой трансформации, на основе ши- рокого спектра показателей официальной статистической отчетности и исследований, проводимых конкретными компаниями.

\section{Литература}

1. Атурин B.B. Управление цифровой трансформацией: научные подходы и экономическая политика / В.В. Атурин, И. С. Мога, С. М. Смагулова // Управленец. - 2020. T. 11. - №2. - С. 67-76.

2. Наука и инновации [Электронный ресурс]. - Режим доступа: https://rosstat.gov.ru/ folder/14477 (Дата обращения: 19.06.21).

3. Золотарева О.А., Давлетшина Л.А. O мониториге социально-экономических последствий цифровой трансформации / Научные труды вольного экономического общества России. - 2021. - Т. 28. — №2. С. $380-400$.

4. Официальный сайт «Технологии, инжиниринг, инновации» [Электронный ресурс]. - Режим доступа: https://integral-russia. ru/o-nas_1-2/ (Дата обращения: 20.02.2021).

5. Официальный сайт Conews [Электронный ресурс]. - Режим доступа: https://www. cnews.ru/news/line/2021-02-08_s7_airlines_i reksoft_podveli (Дата обращения: 22.05.2021).

6. Паспорт национального проекта Национальная программа «Цифровая экономика Российской Федерации» [Электронный ресурс]. - Режим доступа: https://digital.gov. ru/uploaded/files/natsionalnaya-programmatsifrovaya-ekonomika-rossijskoj-federatsii $\mathrm{NcN} 2 n O O . p d f$ (Дата обращения: 12.05.2021).

7. Попов В.Н. Интеллектуальные высокопроизводительные методы автоматизированного проектирования технологических процессов машиностроительной продукции в веб среде / В.Н. Попов, А. В. Кораблев [Электронный ресурс]. - Режим доступа: http:// технологииинноваций.pф/140t_tehnologii1. html (Дата обращения: 18.02.2021).

8. Сергеев Л.И. Цифровая экономика. Учебник для вузов / Л.И. Сергеев, А. Л. Юданова. Под редакцией Л.И. Сергеева. - М.: Издательство Юрайт, 2020. - 332 с.

9. Федеральные статистические наблюдения по социально-демографическим проблемам [Электронный ресурс]. - Режим доступа: https://rosstat.gov.ru/itog_inspect (Дата обращения: 12.05.2021). 
10. Цифровизация промышленности [Электронный ресурс]. - Режим доступа: https://center2m.ru/tsifrovizatsiya-promishlenosti (Дата обращения: 19.06.2021).

11. Цифровая экономика России 2024 [Электронный ресурс]. - Режим доступа: https://data-economy.ru/2024 (Дата обращения: 10.05.2021).

\section{References}

1. Aturin V.V. Upravlenie cifrovoj transformaciej: nauchnye podhody i jekonomicheskaja politika [Management of digital transformation: scientific approaches and economic policy]/ V.V. Aturin, I.S. Moga, S.M. Smagulova // Upravlenec [Manager]. — 2020. — Vol. 11. №2. - Pp. 67-76.

2. Nauka i innovacii [Science and Innovation] [Jelektronnyj resurs]. — URL: https:// rosstat.gov.ru/folder/14477 (Date accessed: 19.06.21).

3. Zolotareva O.A., Davletshina L.A. O monitorige social'no-jekonomicheskih posledstvij cifrovoj transformacii [On monitoring the socio-economic consequences of digital transformation] / Nauchnye trudy vol'nogo jekonomicheskogo obshhestva Rossii [Scientific Works of the Free Economic Society of Russia]. 2021. - Vol. 28. - №2. - Pp. 380-400.

4. Oficial'nyj sajt «Tehnologii, inzhiniring, innovacii» [The official website of «Technologies, engineering, innovations»] [Jelektronnyj resurs]. - URL: https://integral-russia.ru/onas 1-2/ (Date accessed: 20.02.2021).

5. Oficial'nyj sajt Conews [The official website of Conews] [Jelektronnyj resurs]. - URL: https://www.cnews.ru/news/line/2021-02-08 s7 airlines_i_reksoft podveli (Date accessed: 22.05.2021).
6. Pasport nacional'nogo proekta Nacional'naja programma «Cifrovaja jekonomika Rossijskoj Federacii» [Passport of the national project National program «Digital Economy of the Russian Federation»] [Jelektronnyj resurs]. - URL: https://digital.gov.ru/uploaded/files/natsionalnaya-programma-tsifrovayaekonomika-rossijskoj-federatsii_NcN2nOO.pdf (Date accessed: 12.05.2021).

7. Popov V.N. Intellektual'nye vysokoproizvoditel'nye metody avtomatizirovannogo proektirovanija tehnologicheskih processov mashinostroitel'noj produkcii v veb srede [Intelligent high-performance methods of computer-aided design of technological processes of machine-building products in the web environment] / V. N. Popov, A. V. Korablev [Jelektronnyj resurs]. — URL: http://технологииинноваций. pф/140t tehnologiil.html (Date accessed: 18.02.2021).

8. Sergeev L.I. Cifrovaja jekonomika. Uchebnik dlja vuzov [Digital Economy. Textbook for universities] / L.I. Sergeev, A.L. Judanova. Pod redakciej L. I. Sergeeva [In L. I. Sergeev (eds.)]. - Moscow: Izdatel'stvo Jurajt, 2020. - $332 \mathrm{p}$.

9. Federal'nye statisticheskie nabljudenija po social'no-demograficheskim problemam [Federal statistical observations on socio-demographic problems] [Jelektronnyj resurs]. URL: https://rosstat.gov.ru/itog_inspect (Date accessed: 12.05.2021).

10. Cifrovizacija promyshlennosti [Digitalization of industry] [Jelektronnyj resurs]. URL: https://center2m.ru/tsifrovizatsiya-promishlenosti (Date accessed: 19.06.2021).

11. Cifrovaja jekonomika Rossii 2024 [Digital Economy of Russia 2024] [Jelektronnyj resurs]. - URL: https://data-economy.ru/2024 (Date accessed: 10.05.2021). 

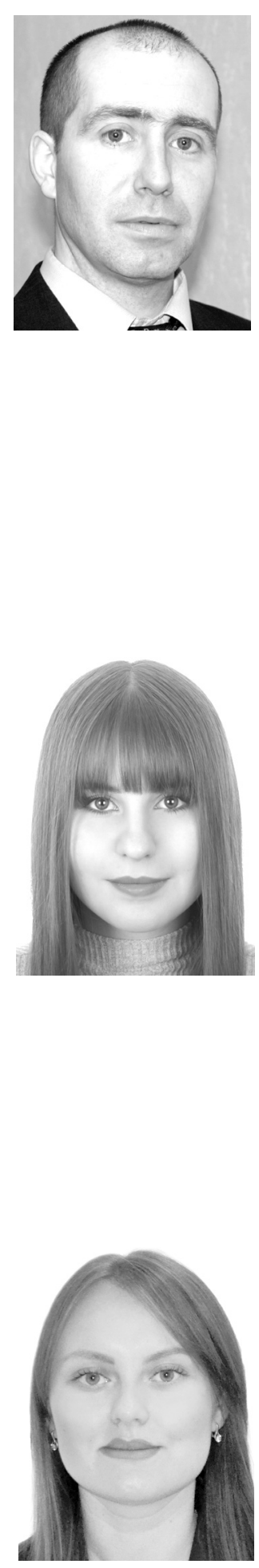

Фраймович Денис Юрьевич - доктор экономических наук, профессор кафедры экономики инноваций и финансов Владимирского государственного университета имени Александра Григорьевича и Николая Григорьевича Столетовых.

Fraimovich Denis Yuryevich - Doctor of Economic Sciences, Professor of the Department of Economics of Innovation and Finance, Vladimir State University named after Alexander and Nikolai Stoletovs.

600005, г. Владимир, ул. Горького, 79

79 Gorkogo st., 600005, Vladimir, Russia, E-mail: fdu78@rambler.ru

Власенко Ксения Андреевна - преподаватель колледжа инновационных технологий и предпринимательства Владимирского государственного университета.

Vlasenko Ksenia Andreevna - Lecturer at the College of Innovative Technologies and Entrepreneurship of Vladimir State University.

600005, г. Владимир, ул. Горького, 79

79 Gorkogo st., 600005, Vladimir, Russia,

E-mail:vla.ksenia@mail.ru

Усова Анастасия Игоревна - магистрант кафедры «Технология машиностроения» института машиностроения и автомобильного транспорта Владимирского государственного университета.

Usova Anastasia Igorevna - Master's Student of the Engineering Technology Department, Institute of Mechanical Engineering and Road Transport, Vladimir State University.

600005, г. Владимир, ул. Горького, 79

79 Gorkogo st., 600005, Vladimir, Russia,

E-mail: nastenalakinsk@mail.ru 